Article

\title{
The Positive Effect of Iron Doping in the Electrocatalytic Activity of Cobalt Hexacyanoferrate
}

\author{
Lijuan Han ${ }^{1}$ and José Ramón Galán-Mascarós ${ }^{1,2, * \mathbb{D}}$ \\ 1 Institute of Chemical Research of Catalonia (ICIQ), The Barcelona Institute of Science and Technology, \\ Av. Països Catalans 16, 43007 Tarragona, Spain; jrgalan@iciq.es \\ 2 ICREA, Passeig Lluis Companys, 23, 08010 Barcelona, Spain \\ * Correspondence: jrgalan@iciq.es
}

Received: 30 December 2019; Accepted: 10 January 2020; Published: 16 January 2020

\begin{abstract}
The lack of an earth-abundant, robust, and fast electrocatalyst for the oxygen evolution reaction (water oxidation) is a major bottleneck for the development of an scalable scheme towards the production of electrolytic hydrogen and other synthetic fuels from renewable energy and natural feedstocks. While many transition metal oxides work reasonably well in basic media, very few alternatives are available in neutral or acidic media. One promising candidate comes from the Prussian blue family, cobalt hexacyanoferrate. This electrocatalyst offers robust activity in a large $\mathrm{pH}$ range $(0<\mathrm{pH}<13)$, although current densities are limited due to slow charge transfer kinetics. Herein, we report how the partial substitution of catalytically active Co centres by additional Fe boosts current densities, reaching over $100 \mathrm{~mA} / \mathrm{cm}^{2}$, more than double the performance of the parent $\mathrm{Co}_{2}\left[\mathrm{Fe}(\mathrm{CN})_{6}\right]$. Those new results clearly increase the opportunity for this catalyst to become relevant in industrial-ready electrolyser architectures.
\end{abstract}

Keywords: electrocatalysis; oxygen evolution reaction; Prussian blue analogues

\section{Introduction}

Prussian blue analogues (PBA) have proven to exhibit a very rich and diverse electrochemistry [1,2]. Their redox properties can be tuned by stoichiometry and oxidation state of the constituent metal centres, incorporation of interstitial ions, or preparation methods. In the cyanide-bridged framework, which forms an infinite, porous 3D network, the $\mathrm{d}$ orbitals of C-bonded metal atoms are stabilised through $\mathrm{d}-\pi^{\star}$ back-donation, while the $\mathrm{d}$ orbitals of $\mathrm{N}$-bonded metals $\mathrm{M}^{\prime}$ are destabilised due to a larger $\sigma$-donating character of the cyanide $\mathrm{N}$-terminal. As a consequence, both positions are inequivalent, controlling the redox properties. In addition, the general deficiency of cyanometallates $\left(\mathrm{M}-\mathrm{M}^{\prime}<1\right)$ generates a lattice of water molecules connecting the coordinatively unsaturated $\mathrm{M}^{\prime}$ positions [3]. As a result, the $\mathrm{M}^{\prime}-\mathrm{OH}_{2}$ centres are electroactive sites with interesting electrocatalytic redox properties [4-6]. Recently, they have been investigated as robust, earth-abundant catalysts for energy conversion applications, including some key processes, such as water oxidation/oxygen evolution (OER) [7-10], oxygen reduction [11-14], and hydrogen peroxide decomposition [15]. Cobalt hexacyanoferrates have been the most promising derivatives towards water oxidation catalysis in acidic and neutral media, thanks to the activity of the $\mathrm{CO}{ }^{\mathrm{II}}$ active centres, whereas the coordinatively saturated $\mathrm{Fe}^{\mathrm{III}}$ moieties play an structural role, participating in the charge transfer dynamics [16,17].

In this direction, we reported how hexacyanoferrate vacancies in cobalt hexacyanoferrate could lead to a higher density of available electroactive Co-aqua sites. However, this gain was mitigated by a slower charge transport process [10]. Looking for chemical strategies to improve the OER catalytic activity of this family, we looked into doping alternatives. Among PBAs, the all iron Prussian blue exhibits the highest electrical conductivity due to its mixed valence nature, facilitating charge 
delocalization along the $\mathrm{Fe}^{\mathrm{II}}-\mathrm{C}-\mathrm{N}-\mathrm{Fe}^{\mathrm{III}}$ bridges. With this in mind, we decided to investigat the effect of Fe doping on the electrocatalytic activity of cobalt hexacyanoferrate, as a means to improve charge transfer kinetics, intending to enhance its electrocatalytic performance. Here, we disclose how the substitution of $\mathrm{Co}^{\mathrm{II}}$ by $\mathrm{Fe}^{\mathrm{II} / \mathrm{III}}$ enhances the OER activity of these PBA-based electrodes, allowing them to reach very high current densities, in neutral or acidic media, superior to other PBAs, but also to the corresponding phosphate-stabilised metal oxides in the same $\mathrm{pH}$ range.

\section{Results and Discussion}

\subsection{Electrode Preparation}

For the preparation of PBA-modified electrodes, the good adhesion between catalyst crystallites and the underlying conductive substrate (fluoride-doped tin oxide, FTO) is essential to ensure fast electron transfer through the interface. So, we followed a chemical etching method [10] by transformation of a $\mathrm{CoO}_{x}$ film by liquid treatment with hexacyanoferrate. In order to incorporate additional $\mathrm{Fe}$ as the dopant in the Co positions, the corresponding $\mathrm{Fe}$-doped $\mathrm{CoO}_{x}$ films were obtained by using a mixture of cobalt and iron precursor salts, $\left.\mathrm{Co}\left(\mathrm{NO}_{3}\right)_{2}\right)$ and $\mathrm{Fe}(\mathrm{NH} 4)_{2}\left(\mathrm{SO}_{4}\right)_{2}$, in the desired stoichiometry for the preparation of the initial Fe-doped $\mathrm{CoO}_{x}$ film under hydrothermal conditions (see methods section for details). In a second step, the oxide film was transformed into the PBA structure by treatment with an aqueous solution of hexacyanoferrate. The stoichiometry of the intermediate oxide films, and that of the final PBA films, were determined by EDX analysis. The ratio in the as-prepared oxo-hydroxide was in perfect agreement with that of the starting reagents during the synthesis. The oxo-hydroxide transformation into the packed Fe-doped PBA produces an enrichment in Co in the final products, with general formula $\mathrm{Fe}_{x} \mathrm{Co}_{2-x}\left[\mathrm{Fe}(\mathrm{CN})_{6}\right]$ (Table S1). For clarity, all samples are labelled as FeCoZ, $(Z=x /(2-x))$, according to the $\mathrm{Fe} / \mathrm{Co}$ ratio $(Z)$ in the water-bound position in the cubic network. All $\mathrm{M}(\mathrm{CN})_{6}$ positions are occupied by Fe coming from the hexacyanoferrate precursor.

\subsection{Electrocatalysis in Neutral pH}

The OER activity of FeCoZ electrodes was investigated by linear sweep voltammetry (Figure 1). The Fe doping does not significantly affect the onset overpotentials, which are almost identical following an analogous trend during the low current regime. Indeed, the Tafel regime is almost identical for all derivatives, with all Tafel slopes in a very narrow range of $\pm 10 \mathrm{mV} /$ decade (Figure S1), in good agreement with the original FeCo0 [10]. This suggests no major changes in the rate-limiting step, and no modifications in the mechanistic pathway.

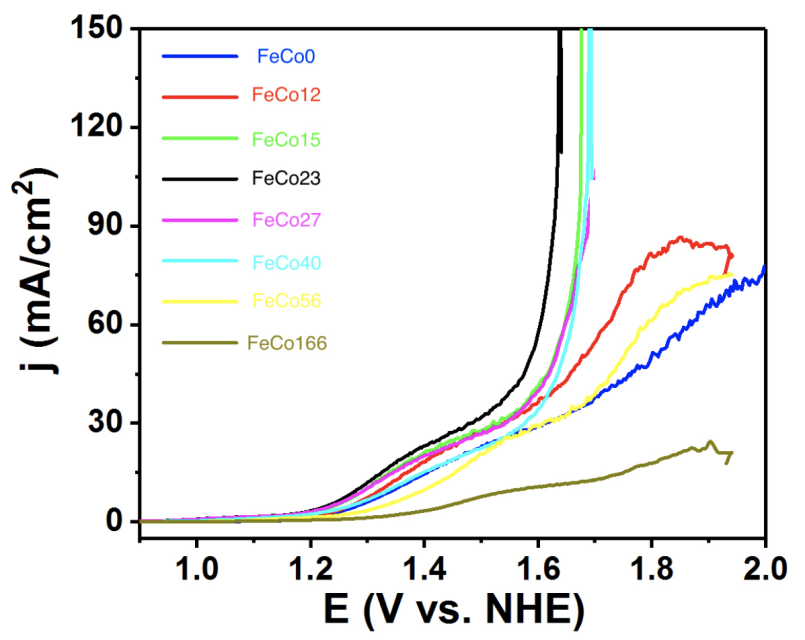

Figure 1. Linear sweep voltammetry recorded $(1 \mathrm{mV} / \mathrm{s})$ for the FeCoZ electrodes. Electrolyte: $0.1 \mathrm{M}$ $\mathrm{KPi}+1 \mathrm{M} \mathrm{KNO}_{3}, \mathrm{pH}=7$. 
However, significant differences appear at higher overpotentials, where the parent $\mathrm{FeCo0}$ enters the diffusion limited range. As $\mathrm{Co}$ is substituted by Fe, enhanced currents appear. FeCo12 already shows a better response, and the initial diffusion limited range is overcome above FeCo15, while the current density keeps increasing very fast, reaching values above $150 \mathrm{~mA} / \mathrm{cm}^{2}$. This enhancement reaches its maximum for about $20 \%$ Fe doping, with additional increments in Fe content becoming detrimental. Overall performance becomes worse than in the original $\mathbf{F e C o 0}$ for $Z>1$. This trend is in agreement with our initial hypothesis. Fe doping is not directly improving (at least significantly) the catalytic activity of the Co centers, but improving the charge transfer, allowing to reach higher current densities. However, as Fe doping increases, this also decreases the density of active sites, since Fe is not active for OER at this overpotentials and conditions, as confirmed by the inactivity of the all iron Prussian blue [18].

Taking the overpotentials at $100 \mathrm{~mA} / \mathrm{cm}^{2}$, a volcano trend was found, indicating an optimum composition around $20 \%$ for FeCo23 (Figure 2). We compared the activity of this FeCo23 with that of both oxo-hydroxide precursors, $\mathrm{FeCoO}_{x}$ and $\mathrm{Co}(\mathrm{OH})_{x}$-intermediate phases in its preparation. As shown in Figure 3, FeCo23 performance is superior to all of them, especially at high current densities, easily reaching $100 \mathrm{~mA} / \mathrm{cm}^{2}$ when all other catalysts are entering what appears to be a diffusion limited regime (Table S2).

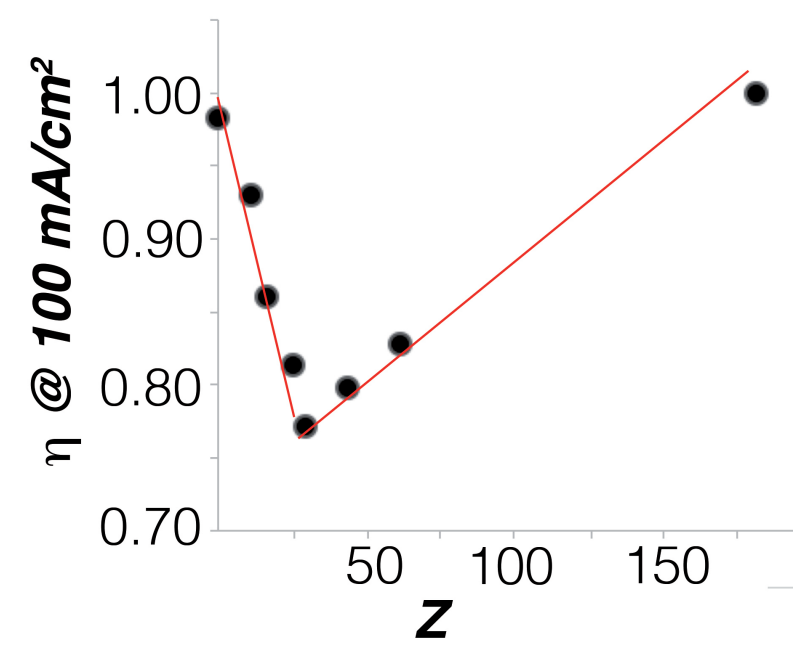

Figure 2. Plot of the overpotential $(\eta)$ needed to reach a current density of $100 \mathrm{~mA} / \mathrm{cm}^{2}$ in the series of FeCoZ anodes. Electrolyte: $0.1 \mathrm{M} \mathrm{KPi}+1 \mathrm{M} \mathrm{KNO}_{3}, \mathrm{pH}=7$.

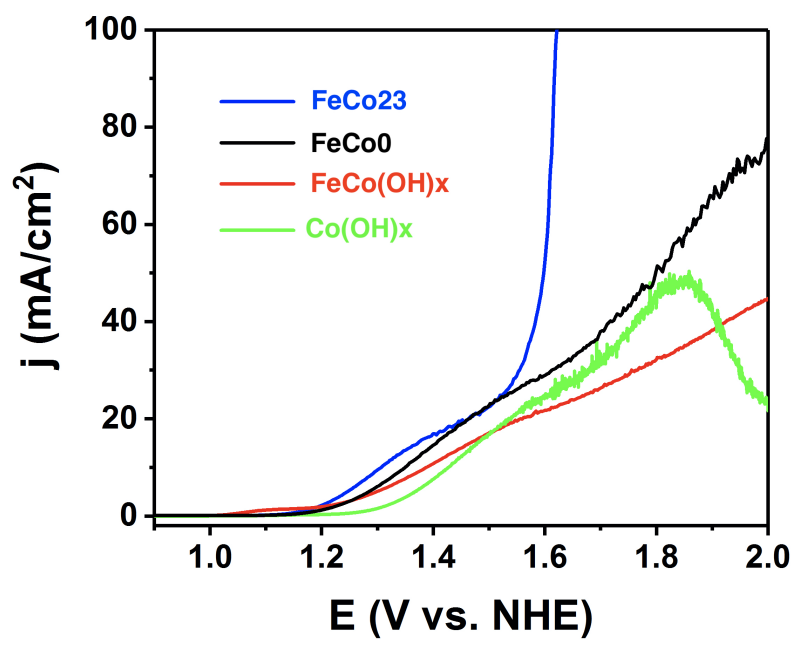

Figure 3. Comparative linear sweep voltammetry $(1 \mathrm{mV} / \mathrm{s})$ for the FeCo23 compared with the related oxo-hydroxides. Electrolyte: $0.1 \mathrm{M} \mathrm{KPi}+1 \mathrm{M} \mathrm{KNO}_{3}, \mathrm{pH}=7$. 
To confirm the electrocatalytic durability in water oxidation conditions, amperometric measurements were performed at an applied overpotential of $425 \mathrm{mV}$ (Figure 4). FeCo23 displayed relatively stable electrocatalytic activity, analogous to the parent CoFe PBA. We characterised the electrocatalysts after eight hours under aqueous electro-oxidation conditions to identify any change or evolution in their structure, composition, or morphology. Electron microscopy confirmed the cubic structure is well-preserved, without suffering any significant changes in size, homogeneity, or aggregation (Figure S2). Elemental analysis did not show any evidence of leaching, or additional changes on catalysts composition. Further characterisation with Raman spectroscopy, a surface sensitive technique, confirmed no significant surface evolution occurs during working conditions (Figure S3), suggesting these catalysts are robust, and genuine catalysts in these conditions.

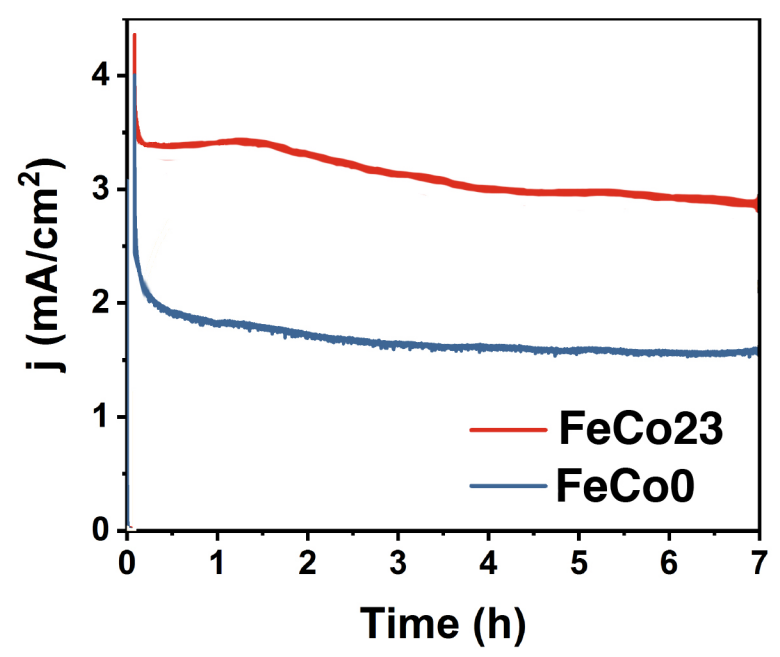

Figure 4. Comparative chronoamperometry with FeCo23 or FeCo0 electrodes. Electrolyte: $0.1 \mathrm{M} \mathrm{KPi}+$ $1 \mathrm{M} \mathrm{KNO}_{3}, \mathrm{pH}=7$.

\subsection{Electrocatalysis in Acidic $p H$}

One of the most promising features of PBAs is their stability in acidic environments, where only noble metals are suitable electrocatalysts for OER, due to the intrinsic instability of alternative earth-abundant metal oxides. The latter just dissolve in such working conditions [19-21]. Indeed, FeCo0 was already incorporated into polymer electrolyte membrane (PEM) electrolysers with promising results [22], limited by the slow charge transfer of this material, requiring additional conducting support. The FeCoZ series shows enhanced performance for OER in acidic media (Figure 5a). For instance, the current density still rises sharply in a $\mathrm{H}_{3} \mathrm{PO}_{4} \mathrm{pH}=1.5$ solution with $\mathrm{KNO}_{3}(1 \mathrm{M})$ electrolyte. However, at this $\mathrm{pH}$, the performance is not as robust as in neutral media. We found a continuous decrease with time at $\mathrm{pH}<1.5$ (Figure $5 \mathrm{~b}$ ). 


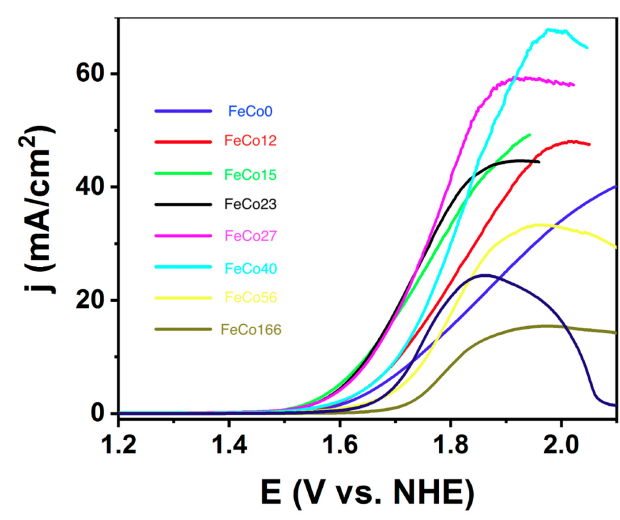

(a)

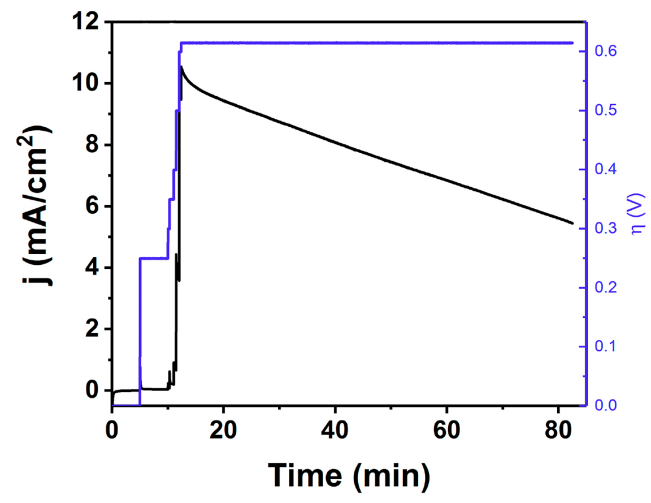

(b)

Figure 5. (a) Linear sweep voltammetry $(1 \mathrm{mV} / \mathrm{s})$ with FeCoZ electrodes. (b) Chronoamperometry with a FeCo23 electrode. Electrolyte: $\mathrm{H}_{3} \mathrm{PO}_{4} \mathrm{pH}=1.5$ solution with $\mathrm{KNO}_{3}(1 \mathrm{M})$ electrolyte.

\section{Conclusions}

In summary, we have demonstrated the validity of our initial hypothesis. The slow charge transfer kinetics of the water oxidation electrocatalyst $\mathrm{Co}_{2}\left[\mathrm{Fe}(\mathrm{CN})_{6}\right]$ can be overcome by doping with $\mathrm{Fe}$ in the series $\mathrm{Fe}_{x} \mathrm{Co}_{2-x}\left[\mathrm{Fe}(\mathrm{CN})_{6}\right]$, based on the positive effect of the mixed-valence nature introduced by the $\mathrm{Fe}^{I I}-\mathrm{CN}-\mathrm{Fe}^{I I I}$ pairs. We found optimum performance in $x \approx 0.4$. The enhancement is particularly relevant at high current densities, one of the flaws of PBAs, for which it was able to support robust OER, but at limited currents. In the past, combination with conducting supports and nanostructuration were tested as plausible solutions to the problem. This new strategy opens an easier and simple alternative for further implementation into industrial electrolysers.

\section{Materials and Methods}

$\left[\mathrm{Fe}_{x} \mathrm{Co}_{(2-x)}\left[\mathrm{Fe}(\mathrm{CN})_{6}\right]\right.$ : Iron and cobalt oxo/hydroxides were prepared following a procedure from the literature [10], using a $\mathrm{Co} / \mathrm{Fe}$ mixture with the desired ratio. Briefly, $\mathrm{Co}\left(\mathrm{NO}_{3}\right)_{2} \cdot 6 \mathrm{H}_{2} \mathrm{O}(77.5 \mathrm{mg})$, the desired stoichiometric amount of $\mathrm{Fe}\left(\mathrm{NH}_{4}\right)_{2}\left(\mathrm{SO}_{4}\right)_{2} \cdot 6 \mathrm{H}_{2} \mathrm{O}$, and urea $(80.8 \mathrm{mg})$ were dissolved in $10 \mathrm{~mL}$ MilliQ water and transferred into a $20 \mathrm{~mL}$ Teflon-lined autoclave, with a FTO glass substrates immersed in the solution. The autoclave was maintained at $120^{\circ} \mathrm{C}$ for $10 \mathrm{~h}$ and then cooled down to room temperature in air. Then, the coated FTO glass was rinsed with MilliQ water several times. Subsequently, the electrode was immersed in $9 \mathrm{~mL}$ of the freshly prepared $\mathrm{K}_{3} \mathrm{Fe}(\mathrm{CN})_{6}$ aqueous solution $(800 \mathrm{mg} / 100 \mathrm{~mL})$ in a sealed glass vial and heated at $60^{\circ} \mathrm{C}$ for $24 \mathrm{~h}$. During the reaction, the oxide starting material dissolved, being substituted by the Prussian blue derivative with the stoichiometry defined by the initial film. Finally, the electrodes were gently rinsed with MilliQ water, and left in an acid bath overnight to remove any remaining traces of oxo-hydroxide.

All electrochemical experiments were performed at the ambient conditions with a Bio-Logic VMP3 multichannel potentiostat/galvanostat. The three-electrode configuration was completed with a saturated calomel electrode (SCE) reference electrode, and a Pt mesh counter electrode. All potentials were measured against $\mathrm{SCE}$, and are reported versus the normal hydrogen electrode (NHE) using the equation of $E(\mathrm{NHE})=E(\mathrm{SCE})+0.244 \mathrm{~V}$. Overpotentials were computed using $\eta=E(\mathrm{NHE})-1.229$ $+0.059 \mathrm{pH}$. Ohmic drop was corrected for all electrochemical data by using the automatic current interrupt $(\mathrm{CI})$ method implemented by the potentiostat software. In all cases, $0.1 \mathrm{M}$ of phosphate buffer $(\mathrm{KPi})$ solution at $\mathrm{pH}=7$ was firstly prepared by dissolving appropriate amounts of $\mathrm{K}_{2} \mathrm{HPO}_{4}$ and $\mathrm{KH}_{2} \mathrm{PO}_{4}$ solid in $1 \mathrm{M} \mathrm{KNO}_{3}$ solution. The $\mathrm{pH}$ was gradually increased or decreased by adding aliquots of concentrated $\mathrm{KOH}$ solution or concentrated $\mathrm{H}_{3} \mathrm{PO}_{4}$ in $\mathrm{pH}=7,0.1 \mathrm{M} \mathrm{KPi}+1 \mathrm{M} \mathrm{KNO}_{3}$ solution, while monitoring with $\mathrm{pH}$ meter. All cyclic voltammograms (CVs) were measured in a three-electrode, one-compartment configuration with $50 \mathrm{~mL}$ aqueous phosphate buffer solution. Linear sweep voltammetry (LSV) data were collected at a scan rate of $1 \mathrm{mV} / \mathrm{s}$, unless otherwise noted. 
Chrono-potentiometric or chrono-amperometric measurements (CPs) were recorded at a constant current density in a fritted $\mathrm{H}$-shaped cell under vigorous stirring. The platinum mesh electrode was inserted into one compartment (cathodic reaction), while the modified working electrode and a reference electrode were inserted in the anodic compartment. Steady-state current densities for Tafel analyses were collected at a variety of applied potentials during oxygen evolution at a constant $\mathrm{pH}$. At each potential, the current was stabilised for $10 \mathrm{~min}$ to attain a steady-state value that was averaged for $30 \mathrm{~s}$ under stirring. All data were recorded at least three times from three different samples, finding good repeatability, with no significant deviations within experimental error.

Scanning electron microscopy (SEM) micrographs were acquired on an FEI Quanta 650 FEG ESEM, $20 \mathrm{kV}$, equipped with an Oxford EDX analyser (Oxford Instruments, Abingdon, UK). A total of $5 \mathrm{~nm}$ Pt was deposited onto the as-prepared PBA samples for SEM checking by using magnetron sputtering LEICA EM ACE600. Infrared transmittance spectra were recorded on a FTIR-ATR Cary 630 TR1 Ph2 spectrometer in the 4000-400 $\mathrm{cm}^{-1}$ region. Raman spectroscopy was collected with a Renishaw in Via Reflex Raman confocal microscope, Gloucester-Shire, UK, light source: $514 \mathrm{~nm}$.

Supplementary Materials: The following are available online at http:/ /www.mdpi.com/2073-4344/10/1/130/s1. Figure S1: Tafel plot obtained with CoFe23 electrodes in pH 7 KPi electrolyte. Figure S2: SEM images of as-prepared CoFe23, and after $10 \mathrm{~h}$ electrolysis at $\eta=500 \mathrm{mv}$ in $\mathrm{pH} 7 \mathrm{KPi}$ electrolyte. Figure S3: Raman spectra of as-prepared CoFe0, CoFe23, and CoFe166; and of CoFe23 after $10 \mathrm{~h}$ electrolysis at $\eta=500 \mathrm{mv}$ in $\mathrm{pH} 7 \mathrm{KPi}$ electrolyte. Table S1: Metal ratio in reagents, and final products for the series $\mathrm{Fe}_{x} \mathrm{Co}_{2-x}\left[\mathrm{Fe}(\mathrm{CN})_{6}\right]$. Table S2: Overpotentials required to reach an specific current density in the FeCoZ series.

Author Contributions: Funding acquisition, J.R.G.-M.; investigation, J.R.G.-M. and L.H.; supervision, J.R.G.-M.; methodology, L.H.; writing-original draft preparation, J.R.G.-M. and L.H. All authors have read and agreed to the published version of the manuscript.

Funding: This work was funded by FEDER/Ministerio de Ciencia, Innovación y Universidades/Agencia Estatal de Investigación (RTI2018-095618-B-100); the Generalitat de Catalunya (2017-SGR-1406); and the CERCA Programme/Generalitat de Catalunya.

Conflicts of Interest: The authors declare no conflict of interest.

\section{Abbreviations}

The following abbreviations are used in this manuscript:

PBA Prussian blue analogues

OER Oxygen evolution reaction

FTO Fluoride-doped tin oxide

\section{References}

1. Karyakin, A.A. Prussian Blue and Its Analogues: Electrochemistry and Analytical Applications. Electroanalysis 2001, 13, 813-819. [CrossRef]

2. de Tacconi, N.R.; Rajeshwar, K.; Lezna, R.O. Metal Hexacyanoferrates:? Electrosynthesis, in Situ Characterization, and Applications. Chem. Mater. 2003, 15, 3046-3062. [CrossRef]

3. Piernas-Muñoz, M.J.; Castillo Martínez, E. Prussian Blue and Its Analogues.Structure, Characterization and Applications. In Prussian Blue Based Batteries; Springer: Cham, Switzerland, 2007; pp. 9-22.

4. Karyakin, A.A. Advances of Prussian blue and its analogues in (bio)sensors. Curr. Opin. Electrochem. 2017, 5, 92-98. [CrossRef]

5. Komkova, M.A.; Karyakina, E.E.; Karyakin, A.A. Catalytically Synthesized Prussian Blue Nanoparticles Defeating Natural Enzyme Peroxidase. J. Am. Chem. Soc. 2018, 140, 11302-11307. [CrossRef] [PubMed]

6. De Lara González, G.L.; Kahlert, H.; Scholz, F. Catalytic reduction of hydrogen peroxide at metal hexacyanoferrate composite electrodes and applications in enzymatic analysis. Electrochim. Acta 2007, 52, 1968-1974. [CrossRef]

7. Pintado, S.; Goberna-Ferron, S.; Escudero-Adan, E.C.; Galan-Mascaros, J.R. Fast and persistent electrocatalytic water oxidation by Co-Fe Prussian blue coordination polymers. J. Am. Chem. Soc. 2013, 135, 13270-13273. [CrossRef] 
8. Alsac, E.P.; Ulker, E.; Nune, S.V.K.; Dede, Y.; Karadas, F. Tuning the Electronic Properties of Prussian Blue Analogues for Efficient Water Oxidation Electrocatalysis: Experimental and Computational Studies. Chem. Eur. J. 2018, 24, 4856-4863. [CrossRef]

9. Aksoy, M.; Nune, S.V.K.; Karadas, F. A Novel Synthetic Route for the Preparation of an Amorphous Co/Fe Prussian Blue Coordination Compound with High Electrocatalytic Water Oxidation Activity. Inorg. Chem. 2016, 55, 4301-4307. [CrossRef]

10. Han, L.; Tang, P.; Reyes-Carmona, A.; Rodríguez-García, B.; Torréns, M.; Morante, J.R.; Arbiol, J.; Galan-Mascaros, J.R. Oxygen Evolution Electrocatalysts Processed by Chemical Etching. J. Am. Chem. Soc. 2016, 138, 16037-16045. [CrossRef]

11. Du, L.; Du, C.; Chen, G.; Kong, F.; Yin, G.; Wang, Y. Metal-Organic Coordination Networks: Prussian Blue and Its Synergy with Pt Nanoparticles to Enhance Oxygen Reduction Kinetics. ACS Appl. Matter. Interfaces 2016, 8, 15250-15257. [CrossRef]

12. Bui, H.T.; Shrestha, N.K.; Cho, K.; Bathula, C.; Opoku, H.; Noh, Y.Y.; Han, S.H. Oxygen reduction reaction on nickel-based Prussian blue analog frameworks synthesized via electrochemical anodization route. J. Electroanal. Chem. 2018, 828, 80-85. [CrossRef]

13. Liu, Y.; Wang, H.; Lin, D.; Zhao, J.; Liu, C.; Xie, J.; Cui, Y. A Prussian blue route to nitrogen-doped graphene aerogels as efficient electrocatalysts for oxygen reduction with enhanced active site accessibility. Nano Res. 2016, 10, 1213-1222. [CrossRef]

14. Jia, S.; Zang, J.; Li, W.; Tian, P.; Zhou, S.; Cai, H.; Tian, X.; Wang, Y. A novel synthesis of Prussian blue nanocubes/biomass-derived nitrogen-doped porous carbon composite as a high-efficiency oxygen reduction reaction catalyst. Electrochim. Acta 2018, 289, 56-64. [CrossRef]

15. Mousavi Shaegh, S.A.; Nguyen, N.-T.; Mousavi Ehteshami, S.M.; Chan, S.H. A membraneless hydrogen peroxide fuel cell using Prussian Blue as cathode material. Energ. Environ. Sci. 2012, 5, 8225-8228. [CrossRef]

16. Moss, B.; Hegner, F.S.; Corby, S.; Selim, S.; Francas, L.; López, N.; Gimenez, S.; Galan-Mascaros, J.R.; Durrant, J.R. Unraveling Charge Transfer in CoFe Prussian Blue Modified $\mathrm{BiVO}_{4}$ Photoanodes. ACS Energy Lett. 2019, 4, 337-342. [CrossRef]

17. Hegner, F.S.; Herraiz-Cardona, I.; Cardenas-Morcoso, D.; López, N.; Galan-Mascaros, J.R.; Gimenez, S. Cobalt Hexacyanoferrate on $\mathrm{BiVO}_{4}$ Photoanodes for Robust Water Splitting. ACS Appl. Mater. Interfaces 2017, 9, 37671-37681. [CrossRef]

18. Goberna-Ferron, S.; Hernández, W.Y.; Rodríguez-García, B.; Galan-Mascaros, J.R. Light-Driven Water Oxidation with Metal Hexacyanometallate Heterogeneous Catalysts. ACS Catal. 2014, 4, 1637-1641. [CrossRef]

19. Gerken, J.B.; McAlpin, J.G.; Chen, J.Y.C.; Rigsby, M.L.; Casey, W.H.; Britt, R.D.; Stahl, S.S. Electrochemical Water Oxidation with Cobalt-Based Electrocatalysts from $\mathrm{pH}$ 0-14: The Thermodynamic Basis for Catalyst Structure, Stability, and Activity. J. Am. Chem. Soc. 2011, 133, 14431-14442. [CrossRef]

20. You, B.; Sun, Y. Innovative Strategies for Electrocatalytic Water Splitting. Acc. Chem. Res. 2018, 51, 1571-1580. [CrossRef]

21. Hunter, B.M.; Gray, H.B.; Müller, A.M. Earth-Abundant Heterogeneous Water Oxidation Catalysts. Chem. Rev. 2016, 116, 14120-14136. [CrossRef]

22. Rodríguez-García, B.; Reyes-Carmona, A.; Jimenez-Morales, I.; Blasco-Ahicart, M.; Cavaliere, S.; Dupont, M.; Jones, D.; Roziere, J.; Galan-Mascaros, J.R.; Jaouen, F. Cobalt hexacyanoferrate supported on Sb-doped $\mathrm{SnO}_{2}$ as a non-noble catalyst for oxygen evolution in acidic medium. Sustain. Energy Fuels 2018, 2, 589-597. [CrossRef]

(C) 2020 by the authors. Licensee MDPI, Basel, Switzerland. This article is an open access article distributed under the terms and conditions of the Creative Commons Attribution (CC BY) license (http:/ / creativecommons.org/licenses/by/4.0/). 